\title{
Vascular responses in chain saw operators
}

\author{
Kathleen M McKenna, A D Blann, Judith A Allen
}

\begin{abstract}
The intensive use of chain saws is associated with development of the hand-arm vibration syndrome (vibration white finger). Objective testing for cold induced vasospasm was carried out on the fingers of 12 chain saw operators and 12 matched control men from a similar working environment. Two of the chain saw operators tested positive for vasospasm in the laboratory and another three had an abnormal result. All of the control subjects tested negative. Measurements of finger blood flow at different temperatures and during vibration of the hand were similar in the chain saw operators and controls. Use of the chain saw did not cause significant alterations in the plasma concentrations of von Willebrand factor antigen in either the long or the short term.
\end{abstract}

(Occup Environ Med 1994;51:366-370)

Chain saw operators were first reported in 1964 to be at risk of developing the hand-arm vibration syndrome. ${ }^{1}$ Despite improvements in the 1970 s designed to dampen vibration and heat the handles of the saws, new cases continued to appear. ${ }^{23}$ This may be because isolation of the vibration actually increased the amount of low frequency vibration transmitted to the operator's hands or because the effectiveness of antivibration mountings may decrease with wear and tear to the saw. ${ }^{4}$

In Northern Ireland, recent questionnaire finger blood flow responses to vibration of the harvesters and healthy control subjects were also examined in the present study.

Raised concentrations of von Willebrand factor antigen ( $v$ WFAg), which is released from endothelial cells, have been reported in patients with the hand-arm vibration syndrome $^{10}$ and so the plasma concentrations of this marker of endothelial damage were also measured.

\section{Subjects and methods \\ SUBJECTS}

All measurements were started early in the morning to ensure that the harvesters had not used a chain saw for at least 16 hours before testing. All smokers refrained from smoking for at least one hour before any measurements were made. Subjects wore light indoor clothing and lay with the arms supported at heart level throughout.

Measurements were made on the corresponding fingers of 12 harvesters, and 12 volunteers from either the watercourse management or forestry maintenance workforce (table 1). These control subjects all worked in an outdoor environment similar to the harvesters but none of them used chain saws in their routine work. They were matched individually to the harvesters for age and smoking habit. Anyone with a history of trauma to the neck, trunk, or upper limbs or on medication with a significant cardiovascular action was excluded. The project had the approval of the local ethics committee and all subjects gave informed written consent.

\section{FINGER BLOOD FLOW MEASUREMENTS}

After a 30 minute equilibration period in a temperature controlled chamber maintained at $20 \pm 0 \cdot 2^{\circ} \mathrm{C}$, finger blood flow was measured in one finger of each hand by venous occlusion plethysmography with fluid filled plethysmographs. ${ }^{11}$ If the subject had symptoms in his fingers, measurements were made on his worst affected finger in each hand, otherwise the middle fingers were used. Corresponding fingers were studied in his matched control subject. Initially the local

Table 1 Chain saw operators and their control subjects

\begin{tabular}{lcc}
\hline & Chain saw operators & Control subjects \\
\hline No of men & 12 & 12 \\
Age range (y) & $23-60$ (mean 35) & $23-64$ (mean 35) \\
Vibration exposure (y) & $2-25$ (mean 12) & 0 \\
\hline
\end{tabular}
surveys by occupational health personnel showed that a considerable proportion of chain saw operators in the forest service were experiencing symptoms suggestive of the hand-arm vibration syndrome. Currently about 80 men are employed as full time chain saw operators (harvesters). They are divided into nine harvesting squads located throughout the province and are supplied with antivibration saws (Husqvarna models 254/G, 262/G, 266XP/XPG). The acceleration levels on the handles are 5-6 $\mathrm{ms}^{-2}$. The present study was designed to identify cases of the hand-arm vibration syndrome in a small sample of harvesters by objective testing for cold induced vasospasm. ${ }^{56}$

Vibration has been shown to reduce finger blood flow in healthy subjects. ${ }^{7}$ Some workers have found the reduction to be greater in men with the hand-arm vibration syndrome ${ }^{8}$ than

in healthy controls but others have not. ${ }^{9}$ The 
finger temperature was $32^{\circ} \mathrm{C}$ and measurements were made over a five minute period. The temperature in the finger plethysmograph was then rapidly decreased to $24^{\circ} \mathrm{C}$ and five minutes later flow was measured for a further five minute period. Values cited are the mean of 20 measurements of finger blood flow made over a five minute period.

\section{OBJECTIVE TESTING FOR VASOSPASM}

This was carried out on the same fingers as mentioned, with laser Doppler flowmetry to measure finger systolic pressure. The method has been described in detail previously. ${ }^{56}$ Finger systolic pressure was measured as the pressure at which red cell flux in the fingertip skin reappeared after digital arterial occlusion. Two measurements were made with the finger at $32^{\circ} \mathrm{C}$ and the mean value was calculated. Finger systolic pressure was then remeasured after five minutes of digital cooling to $15^{\circ} \mathrm{C}$ or $10^{\circ} \mathrm{C}$. If a value of $0 \mathrm{~mm} \mathrm{Hg}$ was recorded after cooling, this indicated complete vasospasm. The severity of cooling required to induce vasospasm gave an indication of the severity of the vasospastic condition. A finger systolic pressure after cooling of more than $0 \mathrm{~mm} \mathrm{Hg}$ but less than $50 \%$ of the precooling value was taken to indicate partial vasospasm.

\section{WHOLE HAND VIBRATION}

Finger blood flow was measured in a room at $24^{\circ} \mathrm{C}$ by venous occlusion plethysmography with strain gauges (Medasonic PMS Inst SG6) positioned just proximal to the nail bed on both middle fingers (fig 1). The right hand rested on a steel plate, the upper surface of which was covered with a thin layer of insulating material to prevent conduction of heat away from the hand. The lower surface of the plate was rigidly attached to a pneumatic chisel (Pnumat, Warrington) driven by compressed air. A reproducible intensity of vibration was induced by accurately controlling air flow to the chisel at a rate of $65 \mathrm{1} / \mathrm{min}$ with a flowmeter (KDG 2000). The left hand was also supported at heart level but received no vibration. Both subjects and investigators wore hearing protection.

Finger blood flow was recorded during a two minute control period, during two minutes of vibration of the plate on which the right hand rested, and for five minutes afterwards. Blood flow was recorded for one minute at 10 and 15 minutes after stopping the vibration.

Six measurements of blood flow were made per minute. Results were calculated as the mean of 12 flows during a control period and the mean of six flows during each minute of vibration and recovery.

The vibration applied to the right hand was analysed by means of an accelerometer (type 4372X, Bruell and Kjaer) attached to the plate beside the middle finger and a real time frequency analyser (type 2143, Bruell and Kjaer).

\section{PLASMA CONCENTRATIONS OF VON}

WILLEBRAND FACTOR ANTIGEN

Blood samples $(10 \mathrm{ml})$ were withdrawn from an antecubital vein on two occasions: firstly, in the laboratory, from 11 harvesters and 11 control subjects after 15 minutes lying at rest in a comfortably warm room at $24^{\circ} \mathrm{C}$ before whole hand vibration was applied; secondly, in a field study, from eight harvesters just before starting work in the morning and again about 4.5 hours later, immediately after laying down their chain saws.

Plasma samples were stored at $-70^{\circ} \mathrm{C}$ until analysis and analysed blind. Concentrations of vWFAg were estimated by an established enzyme linked immunosorbent assay (ELISA) method in 96 well microtitre plates with commercial antisera. ${ }^{12}$

\section{STATISTICS}

Statistical analysis was carried out with the Wilcoxon signed rank test.
Figure 1 (A) Measurement of finger blood flow by venous occlusion plethysmography with a strain gauge $a$ positioned on the distal phalanx and with $a$ pressure cuff $b$ on the pressure cuff $b$ on the
middle phalanx. (B) The hand rested on the plate $c$ welded to the bit of a pneumatic chisel d.

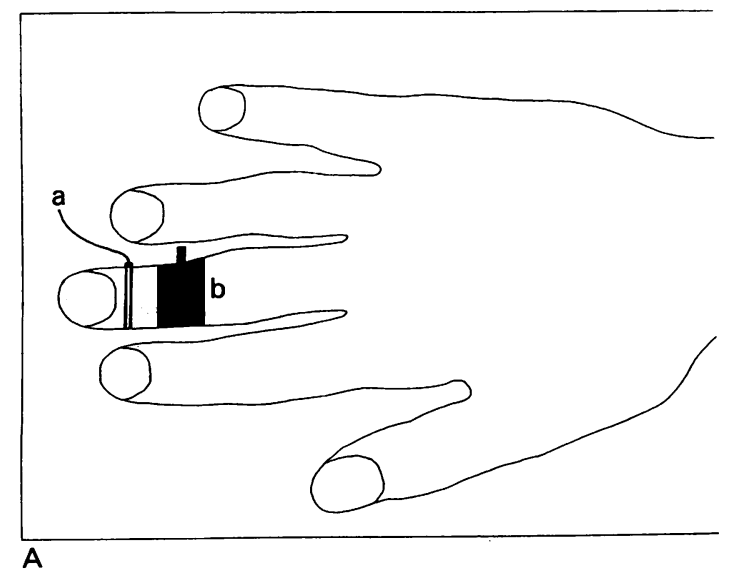


Table 2 Finger blood flow (SEM) ( $\mathrm{ml} / 100 \mathrm{ml} / \mathrm{min})$ in 12 harvesters and 12 matched control subjects at local finger temperatures of $32^{\circ} \mathrm{C}$ and $24^{\circ} \mathrm{C}$

\begin{tabular}{lll}
\hline & \multicolumn{2}{l}{ Finger temperature } \\
\cline { 2 - 3 } & $32^{\circ} \mathrm{C}$ & $24^{\circ} \mathrm{C}$ \\
\hline Harvesters: & $16.0(3 \cdot 6)$ & $7 \cdot 0(2 \cdot 0)$ \\
$\quad$ Right & $16 \cdot 1(3 \cdot 1)$ & $5 \cdot 7(1 \cdot 3)$ \\
Left & $17.4(2 \cdot 0)$ & $6 \cdot 7(1 \cdot 2)$ \\
Controls: & $19 \cdot 3(2 \cdot 5)$ & $7 \cdot 5(1 \cdot 8)$ \\
$\quad$ Right & & \\
\hline Left & & \\
\hline
\end{tabular}

\section{Results}

FINGER BLOOD FLOW MEASUREMENTS

There was no significant difference in finger blood flow in the harvesters and their matched control subjects when the fingers were warm at $32^{\circ} \mathrm{C}$ or cool at $24^{\circ} \mathrm{C}$ (table 2 ).

OBJECTIVE TESTING FOR VASOSPASM

After finger cooling, two of the 12 harvesters had complete vasospasm; one was graded as mild (grade 1) and the other as moderate (grade 2). Three more had an abnormal pattern of prolonged very low laser Doppler flux after cooling. They did not have vasospasm by definition as finger systolic pressures after finger cooling were $98 \cdot 9,93 \cdot 2$, and $68 \cdot 7 \%$ of the precooling values respectively. None of the control subjects showed either vasospasm or an abnormal response.

WHOLE HAND VIBRATION

Figure 2 shows the blood flow in the right and left middle fingers of a chain saw operator before, during, and after two minutes of vibration of the right hand. Blood flow was reduced in both the experimental right and the control left finger during the period of vibration. Flow increased towards resting values immediately the vibration ceased.

This pattern was seen in all 12 harvesters. Blood flow was significantly reduced $(p<$ 0.01 ) in both middle fingers during the first minute of vibration (table 3 ). In the right (vibrated) hand this reduction continued through the second minute of vibration and for one minute after vibration ceased. In the left (non-vibrated) hand, the reduction in blood flow was less pronounced during the second minute of vibration and recovery was immediate when vibration ceased.

In the vibrated hands of the control subjects, finger blood flow was also significantly reduced during vibration, but recovery was immediate. In the non-vibrated hand, finger blood flow was only reduced during the first minute of vibration.

Table 3 shows finger blood flow during and after vibration in the vibrated and nonvibrated fingers of both harvesters and controls with flow expressed as a percentage of the previbration flow. There was considerable variation in finger blood flow within each group of subjects. When the harvesters were directly compared with their matched control subjects, there was no significant difference in the resting previbration finger blood flow measurements, the patterns of response to whole hand vibration, or in the patterns of recovery.
Figure 2 Recordings of middle finger blood flow in the right (vibrated) and left (non-vibrated) hands of a chain saw operator before, during, and immediately after a two minute period of vibration. The value indicated above a particular flow slope indicates the blood flow in $\mathrm{ml} / 100 \mathrm{ml} / \mathrm{min}$. Part of the recording during vibration has been omitted.
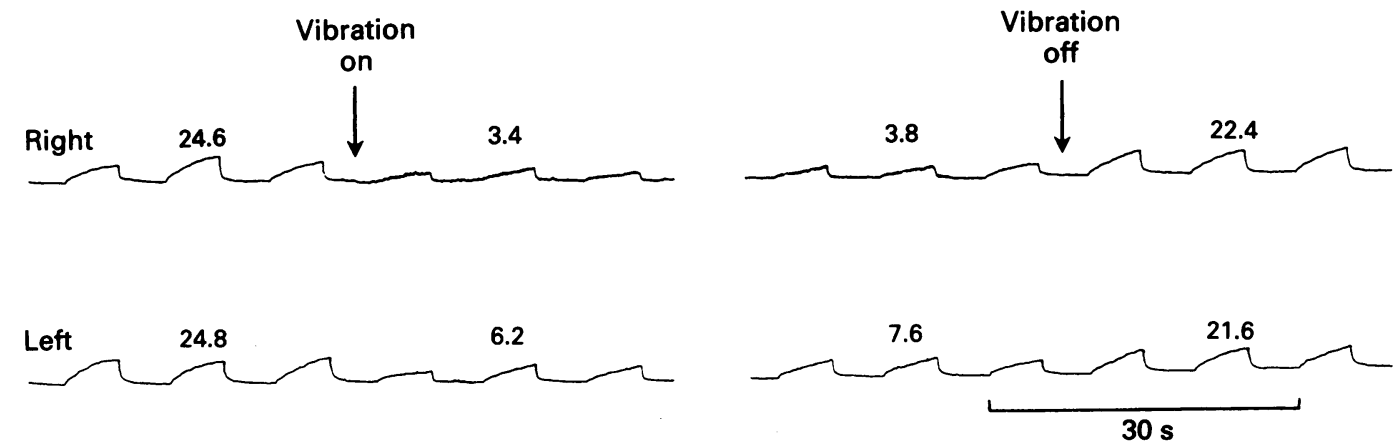

Table 3 Finger blood flow ( $\mathrm{ml} / 100 \mathrm{ml} / \mathrm{min})$ in 12 harvesters and 12 matched control subjects before, during, and after two minutes of vibration

\begin{tabular}{|c|c|c|c|c|c|c|c|c|}
\hline \multirow{5}{*}{$\begin{array}{l}\text { Period } \\
\text { Previbration } \\
\text { Vibration (min): } \\
\text { V } 1 \\
\text { V } 2\end{array}$} & \multicolumn{4}{|l|}{ Harvesters } & \multicolumn{4}{|l|}{ Controls } \\
\hline & \multirow{2}{*}{\multicolumn{2}{|c|}{$\frac{\text { Vibrated }}{\text { Mean (SEM) (\%) }}$}} & \multirow{2}{*}{\multicolumn{2}{|c|}{$\frac{\text { Non-vibrated }}{\text { Mean (SEM) (\%) }}$}} & \multirow{2}{*}{\multicolumn{2}{|c|}{$\frac{\text { Vibrated }}{\text { Mean (SEM) (\%) }}$}} & \multirow{2}{*}{\multicolumn{2}{|c|}{$\frac{\text { Non-vibrated }}{\text { Mean (SEM) (\%) }}$}} \\
\hline & & & & & & & & \\
\hline & $32.5(7 \cdot 7)$ & $(100 \cdot 0)$ & $35 \cdot 4(7 \cdot 7)$ & $(100 \cdot 0)$ & $20.3(3.3)$ & $(100 \cdot 0)$ & $28 \cdot 3(5 \cdot 3)$ & $(100 \cdot 0)$ \\
\hline & $\begin{array}{l}13 \cdot 6(4 \cdot 1)^{\star \star} \\
18 \cdot 2(6 \cdot 1)^{\star \star}\end{array}$ & $\begin{array}{l}(40 \cdot 6) \\
(55 \cdot 3)\end{array}$ & $\begin{array}{l}21.9(4.9)^{\star \star} \\
29.5(7 \cdot 7)^{\star}\end{array}$ & $\begin{array}{l}(61 \cdot 5) \\
(80 \cdot 6)\end{array}$ & $\begin{array}{r}7.5(1 \cdot 7)^{\star \star} \\
12.8(2 \cdot 4)^{\star}\end{array}$ & $\begin{array}{l}(47 \cdot 8) \\
(72 \cdot 2)\end{array}$ & $\begin{array}{l}16.7(3.7)^{\star \star} \\
24.0(4.9)\end{array}$ & $\begin{array}{l}(61 \cdot 8) \\
(93 \cdot 6)\end{array}$ \\
\hline $\begin{array}{ll}\text { Recovery (min): } \\
\text { R } & 1 \\
\text { R } & 2 \\
\text { R } & 3 \\
\text { R } & 4 \\
\text { R } & 5 \\
\text { R } & 10 \\
\text { R } & 15\end{array}$ & $\begin{array}{l}23.6(6 \cdot 1)^{\star \star} \\
33.1(7 \cdot 8) \\
31 \cdot 1(7 \cdot 4) \\
36 \cdot 1(10 \cdot 9) \\
33.4(9 \cdot 2) \\
28 \cdot 9(8 \cdot 7) \\
32.3(9 \cdot 5)\end{array}$ & $\begin{array}{r}(75 \cdot 3) \\
(115 \cdot 2) \\
(105 \cdot 4) \\
(100 \cdot 4) \\
(101 \cdot 6) \\
(88 \cdot 1) \\
(90 \cdot 3)\end{array}$ & $\begin{array}{l}33.6(8.9) \\
44.8(10.6)^{\star} \\
38.2(7 \cdot 3) \\
48.7(13.8) \\
48.2(12.0) \\
37.4(9.0) \\
40.7(12 \cdot 2)\end{array}$ & $\begin{array}{l}(97 \cdot 8) \\
(134 \cdot 7) \\
(120 \cdot 3) \\
(133 \cdot 9) \\
(134 \cdot 0) \\
(105 \cdot 4) \\
(110.1)\end{array}$ & $\begin{array}{l}16.8(2.9) \\
19.2(3.2) \\
18.7(2.9) \\
18.8(3.5) \\
19.6(3.6) \\
18.2(4.3) \\
19.9(4.2)\end{array}$ & $\begin{array}{r}(90 \cdot 2) \\
(107.9) \\
(105 \cdot 7) \\
(105.5) \\
(114.0) \\
(98.3) \\
(113.0)\end{array}$ & $\begin{array}{l}24 \cdot 2(4 \cdot 7) \\
25 \cdot 4(4 \cdot 7) \\
22 \cdot 4(4 \cdot 1) \\
24 \cdot 0(4 \cdot 4) \\
26 \cdot 9(5 \cdot 2) \\
20 \cdot 6(4 \cdot 4) \\
24 \cdot 0(4 \cdot 6)\end{array}$ & $\begin{array}{r}(92 \cdot 1) \\
(95 \cdot 3) \\
(90 \cdot 9) \\
(108 \cdot 1) \\
(121 \cdot 0) \\
(88 \cdot 3) \\
(105 \cdot 7)\end{array}$ \\
\hline
\end{tabular}

$(\%)=$ percentage of previbration value

${ }^{\star} \mathrm{p}<0.05 ;{ }^{\star} \mathrm{p}<0.01 v$ previbration value. 


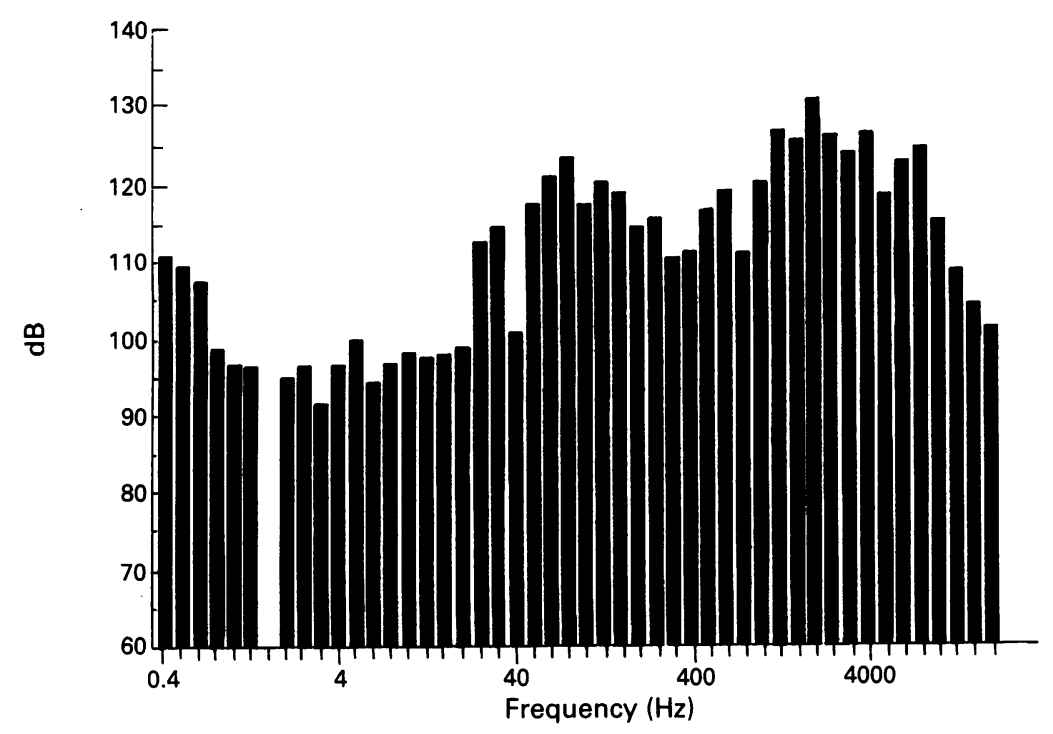

Figure 3 Frequency spectrum recorded from the vibrating plate during an experiment.

\section{VIBRATION ANALYSIS}

Figure 3 shows the frequency spectrum recorded from the plate during an experiment. The highest peaks occurred close to 4 $\mathrm{kHz}$ although there were also prominent peaks in the range $40-400 \mathrm{~Hz}$.

\section{PLASMA CONCENTRATIONS OF VON WILLEBRAND FACTOR ANTIGEN \\ Laboratory study}

There was no significant difference in the concentrations of this substance in the blood samples taken from 11 harvesters and control subjects in the laboratory (table 4). The vWFAg concentration did not seem to be different in those men who exhibited cold induced vasospasm in the laboratory and those who did not.

\section{Field study}

Only eight harvesters volunteered for this part of the investigation. A morning's work did not significantly alter the plasma concentrations of vWFAg (table 5).

\section{Discussion}

Occupational use of chain saws is associated with development of the hand-arm vibration syndrome. ${ }^{1314}$ Considerable effort has been expended, however, over the past 20 years

Table 4 Plasma concentrations of von Willebrand factor antigen in 11 chain saw operators and their matched control subjects in the laboratory

\begin{tabular}{lll}
\hline$v$ WFAg (IUdt $\left.{ }^{-1}\right)$ & Chain saw operators & Controls \\
\hline Mean (SEM) & $64 \cdot 1(11 \cdot 7)$ & $64 \cdot 4(6 \cdot 8)$ \\
Range & $31 \cdot 0-164 \cdot 0$ & $44 \cdot 0-116 \cdot 0$ \\
\hline
\end{tabular}

Table 5 Plasma concentrations of von Willebrand factor antigen in eight chain saw operators in the field before and immediately after a morning's work

\begin{tabular}{lll}
\hline$v W F A g\left(\right.$ IUdl $\left.^{-1}\right)$ & Before work & After work \\
\hline Mean (SEM) & $64 \cdot 9(9 \cdot 4)$ & $60 \cdot 6(7 \cdot 0)$ \\
Range & $25 \cdot 0-100 \cdot 0$ & $26 \cdot 0-83 \cdot 0$ \\
\hline
\end{tabular}

trying to improve the design of saws currently in use. Such measures include incorporation of antivibration mountings and heating of the handles.

Nevertheless, the present study confirms that vibration white finger continues to be a problem in chain saw operators. Two of the 12 harvesters (17\%) had overt vasospastic disease on testing and another three $(25 \%)$ had an abnormal response to cooling. Until further follow up studies are completed, it will not be known if this abnormal response is an early indication of vasospastic disease. It might represent the lower end of the normal range of response. It was not seen in any of the control subjects in the present study, however, and has never been seen in any healthy control subjects studied in our laboratory.

Resting finger systolic pressure was similar in the chain saw operators and controls before testing for vasospasm. This is by contrast with previous findings that chain saw operators had significantly lower resting pressures than the healthy manual workers used as controls. ${ }^{15}$ These authors postulated that chronic exposure to vibration was associated with obstructive changes in the digital arteries and hence reduction in resting finger systolic pressure. The small number of men investigated in the present study and the absence of any with advanced vibration white finger may account for the disparity in findings.

Because the harvesters all work in cold and exposed conditions during the winter, the controls were recruited from men who experienced similar working conditions. The only exclusion criteria for harvesters and controls were a history of injury that might have caused subsequent circulatory problems in the hands or treatment with therapeutic agents that might have interfered with normal vascular reactions. At the time of recruitment to the study, neither the harvesters nor potential control subjects were asked about the occurrence of vascular or neurological symptoms such as coldness, blanching, numbness, or tingling of the fingers. Such symptoms were detailed later at the time of the laboratory visit. This ensured that the two groups were selected in as unbiased a fashion as possible, the only exclusion criteria being a history of trauma or relevant medication.

Once recruited, four of the 12 control men subsequently described symptoms of coldness or numbness in their hands on cold exposure, but none of the 12 controls tested positive for vasospasm or showed an abnormal response to finger cooling in the laboratory.

Resting finger blood flow with the finger warm at $32^{\circ} \mathrm{C}$ or cooler at $24^{\circ} \mathrm{C}$ was similar in the harvesters and their matched controls. This reflected earlier findings in patients with non-occupational Raynaud's disease and a group of vibration white finger claimants composed mainly of riveters and caulkers. ${ }^{56}$

Objective testing showed that two of the 12 harvesters had vasospastic disease. A true incidence or pattern of severity cannot of course be determined from such a small sample but economic constraints on the forestry 
service did not permit a larger number of workers to be studied. It was only possible to study each man on one occasion, so the severity of vasospasm was tested in only one finger of each hand to allow time for the other measurements. Other techniques such as infrared thermography, which could have defined the extent of the phenomenon in each hand, were not available.

In the present study, the application of vibration to one hand caused reductions in finger blood flow in both hands in the harvesters and their matched healthy controls. Similar bilateral reductions in finger blood flow during unilateral hand vibration under laboratory conditions have previously been reported in vibration exposed workers and control subjects. ${ }^{81617}$ Single frequency vibration in the range $80-125 \mathrm{~Hz}$ was reported to be the most effective in provoking digital vasospasm suggesting that a central sympathetic reflex with excitation of the Pacinian corpuscles was involved. In the present experiments, the vibration was generated from a pneumatic air chisel to mimic more closely the complex vibration pattern associated with industrial tools. There was still no evidence that the finger blood flow response to vibration was altered in any way in the harvesters compared with their matched control subjects. Nor was the response either more or less pronounced in those men who had tested positive for vasospasm, thus confirming the findings of Olsen and Petring 9 that the acute response to vibration is not altered in patients with vibration white finger.

Concentrations of vWFAg are raised in inflammatory and non-inflammatory vascular disease. ${ }^{18}$ The similar concentrations in chain saw operators and their controls in the laboratory and the lack of significant alteration in the chain saw operators after a morning's work suggests that any chronic or acute injury to the endothelium must be minor. This contrasts with an earlier report that men occupationally exposed to hand-arm vibration had higher blood concentrations of vWFAg than controls. ${ }^{10}$ It remains possible that accurate detection of changes may have been impeded by sampling from the antecubital site rather than a hand vein. There was no delay in collecting the blood samples after work in the field study as they were obtained as soon as the chain saw was laid down and vWFAg is a relatively stable substance. The most likely possibility is that the vibration exposure did not affect endothelial cell function sufficiently to alter release of vWFAg. These findings are in agreement with previous measurements in riveters. ${ }^{19}$ It is possible that measurement of other markers of endothelial perturbation such as adhesion molecules would be helpful as they reflect activation of cells rather than damage.

Thus it was possible to detect vasospasm in two of the 12 chain saw operators $(17 \%)$ by objective testing. A further three men (25\%) were identified whose abnormal result on testing may progress to full blown vasospastic disease in the future. No abnormalities were detected in the 12 matched control subjects. Neither measurements of finger blood flow nor of plasma concentrations of vWFAg seemed to be particularly helpful in diagnosing vibration white finger or in helping to elucidate underlying mechanisms in the condition.

We are grateful to the Health and Safety Agency for Northern Ireland and to Dr J G Hall and the Employment Medical Advisory Service for their financial support.

1 Grounds MD. Raynaud's phenomenon in the users of chain saws. Med $\mathcal{A}$ Aust 1964;1:901-5.

2 Riddle HFV, Taylor $W$. Vibration-induced white finger among chain sawyers nine years after the introduction of anti-vibration measures. In: Brammer AJ, Taylor W, eds. Vibration effects on the hand and arm in industry. New York: Wiley, 1982:168-72.

3 Brubaker RL, Mackenzie CJG, Hertzman C. Longitudinal study of vibration-induced white finger among coasta ftudy of vibration-induced white finger among coastal fellers in British

4 Griffin MJ. Handbook of Human Vibration. London: Academic Press, 1990:590-1.

5 Allen JA, Devlin MA, McGrann S, Doherty CC. An objec tive test for the diagnosis and grading of vasospasm in patients with Raynaud's syndrome. Clin Sci 1992, 82:529-34.

6 Allen JA, Doherty CC, McGrann S. Objective testing for vasospasm in the hand-arm vibration syndrome. $B r \mathscr{f}$ Ind Med 1992;49:688-93.

7 Welsh CL. The effect of vibration on digital blood flow. $\mathrm{Br}$ f Surg 1980;67:708-10.

8 Hyvarinen J, Pykko I, Sundberg S. Vibration frequencies and amplitudes in the aetiology of traumatic vasospastic and amplitudes in the aetiolog

9 Olsen N, Petring OU. Vibration elicited vasoconstrictor reflex in Raynaud's phenomena. $B r \mathcal{F}$ Ind Med 1988;45 415-9.

10 Ikehata K, Kawauchi S, Kohno F, Nishiyama M, Ide N. Increased platelet function and von Willebrand factor in vibration syndrome. Tokushima $f$ Exp Med 1980;27: 23-8.

11 McGrann S, Irwin ST, Allen JA. A plethysmograph for the measurement of digital blood flow. F Med Eng Technol 1986;10:329-31.

12 Blann AD, Hopkins J, Winkles J, Wainright AC. Plasma and serum von Willebrand factor antigen concentrations in connective $29: 67-71$.

13 Hellstrom $B$, Anderson $\mathrm{KL}$. Vibration injuries in Norwegian forest workers. $\mathrm{Br} \mathcal{F}$ Ind Med 1972;29. 255-63.

14 Harkonen $H$, Riihimaki $H$, Tola $S$, et al. Symptoms of vibration syndrome and radiographic findings in the wrists of lumberjacks. Br $\mathcal{F}$ Ind Med 1984;41:133-6.

15 Matikainen E, Leinonen $H$, Juntunen J, Seppalainen AM. The effect of exposure to high and low frequency handarm vibration on finger systolic pressure. Eur $f$ Physiol arm vibration on

16 Farkkila $M$, Pykko I. Blood flow in the contralateral hand during vibration and hand grip contractions of lumberduring vibration and hand grip contractions of lumber. Scand $\Im$ Work Environ Health 1979;5:368-74.

17 Pykko I, Hyvarinen J, Farkkila M. Studies on the aetiological mechanism of the vasospastic component of the vibration syndrome. In: Brammer $\mathrm{AJ}$, Taylor $\mathrm{W}$, eds. Vibration effects on the hand and arm in industry. New York: Wiley, 1982:13-24.

18 Blann $A$. von Willebrand factor and the endothelium in vascular disease. Br $\mathcal{F}$ Biomed Sci 1993;50:125-34.

19 McKenna K, McGrann S, Blann A, Allen J. An investigation into the acute vascular effects of riveting. $\mathrm{BrF}$ Ind Med 1993;50:160-6. 